International Journal of Applied Linguistics \& English Literature

ISSN 2200-3592 (Print), ISSN 2200-3452 (Online)

Vol. 1 No. 7; November 2012 [Special Issue on Applied Linguistics]

\title{
From Strategic Perspective: Investigating Teacher-Employed Communication Strategies in EFL Classroom Context
}

\author{
Massoud Yaghoubi-Notash (PhD) \\ English Department, Faculty of Persian Literature and Foreign Languages \\ University of Tabriz, P O BOX: 51665331 \\ E-mail: masoud.yaghoubi@gmail.com \\ Mohammad Amin Karafkan \\ English Department, Faculty of Persian Literature and Foreign Languages \\ University of Tabriz, P O BOX: 5166616471 \\ E-mail: amin.karafkan2020@yahoo.com
}

Received: 05-09- 2012

Accepted: 29-10- 2012

Published: 25-11- 2012

doi:10.7575/ijalel.v.1n.7p.145

URL: http://dx.doi.org/10.7575/ijalel.v.1n.7p.145

\begin{abstract}
Various studies have laid emphasis on the nature and patterns of strategy employment in EFL context. Most studies, however, tend to examine those strategies in learner performance. In this study, the researchers investigated the types of communication strategies used by teachers teaching elementary level learners compared to those who are teaching at advanced levels. To this end, 16 (8 elementary and 8 advanced) teachers' verbal classroom performance were recorded and analyzed for characterizing the strategy types. Four full classroom sessions were recorded and transcribed of each teacher's teaching. T-test results indicated that propositional reduction strategies were employed more significantly on the part of teachers teaching advanced-levels. There are a number of important pedagogical implications for teachers and learners regarding teaching experience, syllabus design, and curriculum development which are discussed.
\end{abstract}

Keywords: Communication strategies, Teacher-employed strategies, Avoidance strategy, Message abandonment

\section{Introduction}

Strategies, as goal-oriented procedures, serve a means of achievement. They are quite relevant in the context of second/foreign language communication, and are, therefore, called communication strategies. Gass and Selinker (1994) argue that communication strategies must be employed once the speakers are faced with a need to state a concept or idea in second language but they don't have linguistic resources to do so. The study of communication strategies has been one of the intriguing areas in the field of second language and has given rise to the notion of strategic competence.

Strategic competence deals with knowledge of language and the ability to use it effectively and appropriate to purpose in order to take an active part in communicative interaction (Canale, 1983). According to Rabab'ah (2003),

strategic competence refers to individuals' ability to use [one type of strategy such as] paraphrase, circumlocution, literal translation, lexical approximation, mime, to get his or her massage across and to compensate for a limited or imperfect knowledge of rules or interference of such factors such as fatigue, distraction, or inattention (p.189).

Similarly, Taron and Yule (1989) believed that "strategic competence is also gauged not by degree of correctness but by degree of success or effectiveness" (p.103). There are two areas that involve strategic competence based on Tarone and Yule's (ibid) views: a) the use of communication strategies by speakers or listeners when a problem arises in the process of transmitting information, and b) the overall skill of listeners in successfully transmitting the information to a listener and interpreting the transmitted information. 
International Journal of Applied Linguistics \& English Literature

ISSN 2200-3592 (Print), ISSN 2200-3452 (Online)

Vol. 1 No. 7; November 2012 [Special Issue on Applied Linguistics]

Communication strategies can also be described as compensatory strategies (Poulisse, 1990):

compensatory strategies are processes, operating on conceptual and linguistic knowledge representations, which are adopted by language users in the creation of alternative means of expression when linguistic shortcomings make it impossible for them to communicate their intended meanings in the preferred manner (pp.192-3).

Ellis (2004) adds that "speakers employ them when they have to communicate meanings for which they lack or cannot access the requisite linguistic knowledge therefore, they are seen as compensatory in nature" (p.74).

Many models have been introduced by scholars (see Taron, 1977; Varadi, 1980; Faerch and Kasper, 1983a, b; Blum-Kulka and Levenston's, 1983; Littlewood, 1984; Paribakht's, 1985; Poulissee, 1987; Ellis, 1994; Dornyei, 1995; Slezak-Swat, 2008). Among the many model, the one presented by Dornyei (1995) is most recurrently cited in literature and which is based on Tarone (1977), Varadi (1980), and Faerch and Kasper (1983a, b). The improvement and innovation introduced by Dornyei (ibid) is that two opposite directions in communication strategies are revealed by two branches given by Dornyie: a) avoidance strategies, and b) compensating strategies.

Researchers such as Oxford (1990a), Cohen (1987), and O'Mallay and Chamot (1990) tend to emphasize that efficient learners use different strategies and techniques in order to solve problems that they encounter while acquiring or producing the language. Avoidance, being a common phenomenon in second/foreign language learning and use, is in effect a type of communication strategy. The appropriate employment of avoidance strategies can help learners conduct their communicative goals, keep the learning channels open, and draw more comprehensible input, which are useful to the promotion of communicative competence. On the other hand, overuse or misuse of avoidance might cause the fossilization of learners' interlanguage (Pazhakh, 2006). Also, Pazkhakh (ibid) found a reverse effect of the interlocutor's proficiency level on the frequency of avoidance strategy use (as a subcategory of propositional reduction strategies).

Therefore, “...avoidance is an important issue for second language acquisition research” (Ellis, 1994, p. 68). However, despite its importance, studies on avoidance, especially the empirical ones are far from abundant (Pazhakh, 2006).

Avoidance strategies can be further broken down in to several subtypes such as phonological, syntactic or lexical avoidance and topic avoidance (Brown, 2000). Learners may use topic avoidance or massage abandonment, reduce, alter or replace the content of massage in order to keep the massage within their communicative repertoires (Somsai, 2011). Pazhakh (2006) also argues that

appropriate employment of avoidance strategies can help learners carry out their communicative goals, keep learning channels open and draw more comprehensible input which are beneficial to the development of communicative competence. The learners use avoidance consciously or subconsciously, which is a type of communication strategy (p.2).

Compensating strategies involve compensation for missing knowledge (Brown, 2000, p.129) and are enumerated by (Dornyei, 1995) as follows:

- circumlocution,

- approximation,

- word coinage,

- $\quad$ refabricated patterns,

- $\quad$ appealing for help, and

- $\quad$ stalling or time-gaining strategies

:

Most of the studies on this area have investigated strategy employment in oral production. Bialystok (1983), in an attempt to provide a taxonomy of communication strategies, conducted a study to investigate the effect of proficiency level and task type on the choice of the communication strategy type. Results showed that L2-based strategies were the most effective, and the best strategies users were those who had adequate proficiency in L2 and were capable of modifying their strategy selection. Bialystok (ibid) also reported that despite the differences among the subjects in formal proficiency level and in their own experiences with the target language, their communication strategies on the task could simply be described in terms of a distinction between L1-based 
International Journal of Applied Linguistics \& English Literature

ISSN 2200-3592 (Print), ISSN 2200-3452 (Online)

Vol. 1 No. 7; November 2012 [Special Issue on Applied Linguistics]

strategies and L2-based strategies. Hence, she classified the different strategies employed according to L1 or L2 based strategies (Bialystok, 1983).

Haastrup and Phillipson (1983) confirmed Bialystok's findings in that IL-based (interlanguage-based) strategies seemed to be less effective in achieving the communicative goal. They carried out a study to see where communication broke down and what resources the subjects drew on to cope with their communication problems. They could identify when communication was disrupted and what achievement strategies were employed in the classroom interaction. The investigation revealed that most of the learners, surprisingly, resorted to L1-based strategies more frequently despite their five years of studying EFL, which accounted for only a partial comprehension on the part of the native speakers as interlocutors. However, the IL-based strategies employed by the learners in Haastrup and Phillipson (ibid), in line with Bialystok (1983), were reportedly more effective in achieving full comprehension and complete mutual understanding compared to the L1-based strategies.

Tarone and Yule (1987) also investigated the communication strategies of second language learners using task-based methodology. The strategies employed by the non-native speakers were circumlocution (giving descriptions), appeal, literal translation, mime, and message abandonment. Native speakers were found to resort more dominantly to circumlocution and approximation than non-native speakers did. Additionally, non-native speakers gave more details in their description than native speakers did who, in turn, felt that extra details were not necessary.

Jamshidnejad (2011) explored how a group of language learners develop the accuracy level of their target language in oral communication when they encounter the problem and found out that communication strategy usage in L2 interpersonal communications enables participants to promote accuracy level of their target language. Mei (2010) conducted a research on the use of communication strategies by Chinese EFL learners and his findings demonstrated that students' use of communication strategies was influenced by three variables, namely task type, proficiency level, and academic major.

Chen (1990) claims that self-repetition strategy is used more dominantly by the native speakers to solve the communication breakdown. On the other hand, Applegate (1980) implicitly confirms that native speakers and teachers (as high-proficiency interlocutors) use communication strategies to solve similar problems as well. Other studies have been carried out to investigate the type of communication strategies used by Iranian EFL learners, i.e. the local context of the present study (Ansarin, 2003; Yarmohammadi and Saif,1992). DordiNezhad, Ashouri, Hakimi et al., (2011) in a study concentrating on the Iranian context raise the issue of teachers' communicative styles within a communicative syllabus in the Iranian classrooms claiming that diversity of context and culture challenge the communicative nature of the classroom interaction, which might be a rather remote clue as to the teacher-initiated, and teacher-employed strategic language use.

The specific interactional role of the teacher, whether strategic or other, in the classroom remains largely under-investigated in the core SLA literature, however. When seen from the perspective of classroom discourse, the classroom discourse is closely associated with power relations in which the teacher is assumed to be the most powerful figure. Van den Berg (1988), for instance, suggests that it is the teacher "who regulates verbal behavior and thereby determines to a large extent the type and nature of verbal exchanges in the classroom." (p. 251) . However, to the best of the authors' knowledge, no study has ever explicitly addressed communication strategy employment on the teachers' part in the classroom interaction. Therefore, it remains a largely untouched area, and therefore a motivation for the present study to address the gap in the literature. Specifically, this research aims at exploring the communicative strategy employment by the teachers teaching the elementary vs. those teaching advanced EFL classrooms.

\section{Methodology}

\subsection{Participants}

The researchers focused on sixteen teachers eight of whom were teaching at elementary-level spoken English courses and the remaining 8 teaching at advanced-level spoken-English courses. They were affiliated with six private language institutes in Tabriz, Eastern Azerbaijna province northwest of Iran. Therefore, participants included 16 EFL teachers aged between 23 and 26. The focus on teachers as strategy employers did not mean excluding the 132 learners involved; in fact, the study can be argued to have concentrated upon the classroom discourse going on among the learners and the teachers as interlocutors. The teachers were both experienced and academically-educated in TEFL (Teaching English as a Foreign Language). 
International Journal of Applied Linguistics \& English Literature

ISSN 2200-3592 (Print), ISSN 2200-3452 (Online)

Vol. 1 No. 7; November 2012 [Special Issue on Applied Linguistics]

\subsection{Materials and Procedures}

The researchers used an IC-recorder to record the entire classroom discourse between teachers and students. Note papers had been prepared to jot down any specific information like the number of the participants, the number of the sessions and the number of written words on the board, and teacher-initiated dictionary use as a strategy type. It was impossible for the researchers to video-record the class due to local policies in the institutes.

Altogether, 85 hours and 33 minutes of all classrooms discourse between the teachers and learners that is 43 hours and 3 minutes from each level were recorded. The participating teachers were initially briefed up on the overall framework, but the objective of the study was not disclosed to them since it might have influenced their performance. Data transcription was adapted from Van Lier (1988). An introspective measure called stimulated recall (SR) was employed to obtain some data such as avoidance strategies data which were not clear in data coding. SR is an effort on the researchers' part to explore the speaker's thought processes or strategies and prompts the speaker to recall and report thoughts that he /she had while participating in an event (Mackey and Gass, 2005). Since the present study aims to cover intra-individual (conveying meaning) as well as inter-individual features of communication strategies (requiring the listener to be involved in the conversation), it would have been inconvenient to operationalize the classroom discourse based on only one taxonomy from the literature. Consequently, in order to embrace a comprehensive inventory of strategies, the model by Dornyie and Scotts (1997) and the two taxonomies by Tarone (1981), Faerch and Kasper (1983a) were combined with three communication strategies from Paribakht's taxonomy (1985) along with three newly found ones that emerged in the local context of the study. The latter emerging strategies were named example sentences, writing or spelling words, and dictionary check. Nonverbal strategies such as miming and gestures could, however, not be recorded and were therefore ignored. The integrated model appears in Appendix 1.

A colleague was provided with a prior instruction to code the transcribed data to establish consistency of data coding. The inter-rater reliability turned out to be Kappa $=0.87$. All the data analysis was done by SPSS 17.

\section{Data Analysis and Results}

In analyzing data, first the descriptive data were analyzed. The means of strategy uses by elementary vs. advanced students were calculated, which are shown in Figures 1 and 2.

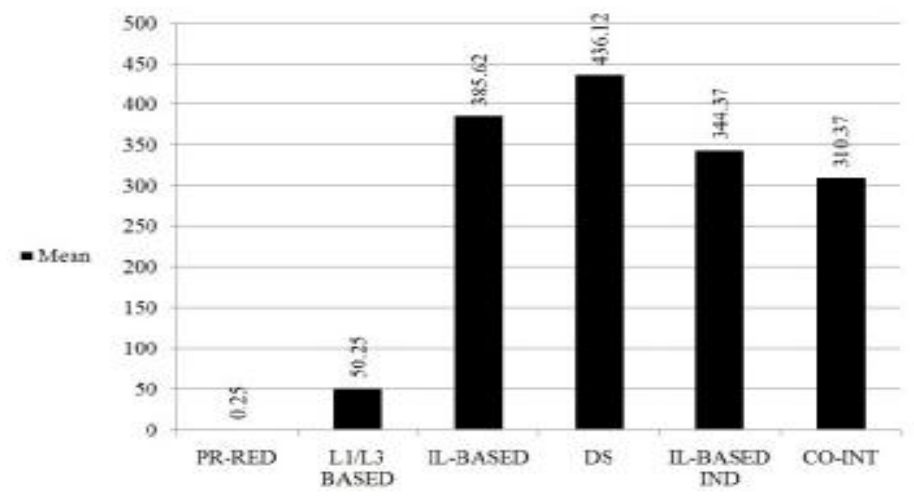

Figure 1. Teachers' use of the categories of communication strategies at elementary level (first group)

PR-RED = propositional-reduction; IL-BASED = interlanguage-based; DS = direct strategies;

IL-BASED IND = interlanguage-based indirect; CO-INT = cooperative interactive

As can be seen in the figure above, the propositional strategy is the smallest in terms of mean (0.25). The L1/L3 based (50.25) stands for a slightly higher mean value. The others are quite close in value, while the highest represents direct strategies (436.12).

With the advanced level, the pattern is quite similar. As can be seen in Figure 2, the propositional strategies category is the smallest in value (6.50), and the L1/L3 based is 58. Direct strategies, like those at the elementary-level, is the highest-frequency category employed by advanced teachers. Again the remaining ones are around the same range, that is between 310 and 386. 
International Journal of Applied Linguistics \& English Literature

ISSN 2200-3592 (Print), ISSN 2200-3452 (Online)

Vol. 1 No. 7; November 2012 [Special Issue on Applied Linguistics]

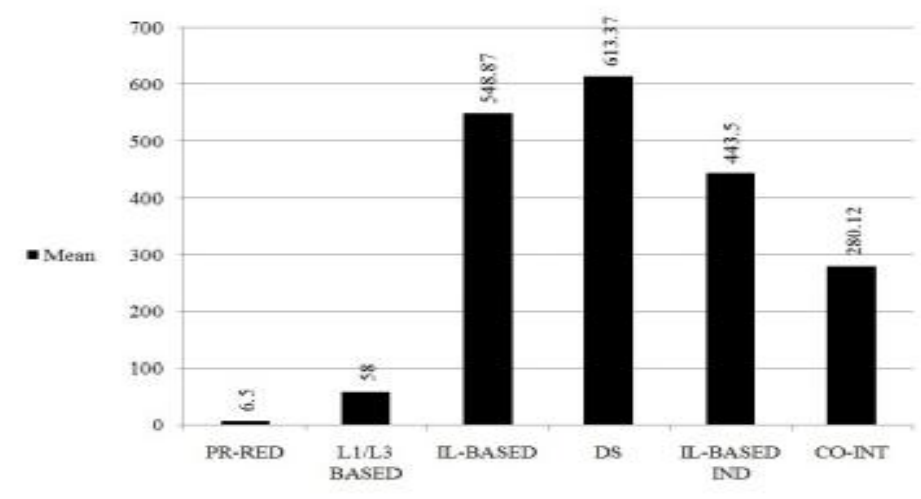

Figure 2. Teachers' use of the categories of communication strategies at advanced level (second group)

PR-RED = propositional-reduction; IL-BASED = interlanguage-based; DS = direct strategies;

IL-BASED IND = interlanguage-based indirect; CO-INT = cooperative interactive

Beyond mere descriptions, t-test results comparing the data revealed remarkable differences regarding the strategy employment. Table 1 illustrates t-test results for each strategy type compared across elementary and advanced level teachers in their corresponding teaching classrooms.

Table 1. Independent-sample t-test results for strategy types employed by elementary vs. advanced teachers

\begin{tabular}{llll}
\hline Strategy Type & t-value & df & Sig. \\
\hline Propositional reduction strategies & $-2.76^{*}$ & 14 & 0.01 \\
\hline L1/L3-based strategies & -0.29 & 14 & 0.77 \\
\hline IL-based strategies & -1.91 & 14 & 0.07 \\
\hline Direct strategies & -1.81 & 14 & 0.91 \\
\hline IL-based (indirect strategies) & -1.50 & 14 & 0.15 \\
\hline Interactional equal variances (cooperative strategies) & -0.60 & 14 & 0.55 \\
\hline
\end{tabular}

According to the information in Table 1, the mean difference between elementary and advanced level teachers' employment of propositional strategy is significant at $p<0.05$. This being so, it can be claimed that the mean of propositional strategy employment on the part of advance-level teachers regarding (i.e., 6.50) is significantly higher than the mean of the elementary-level teachers' employment of the same strategy (i.e. 0.25). Regarding the other strategy types, there was no significant difference between the two groups.

\section{Discussion and Conclusion}

Results indicated that propositional reduction strategy is much less frequently used by both groups of teachers than other strategy types. Nevertheless, when comparing the two groups of teachers, a significant difference in using propositional-reduction strategy (avoidance and message abandonment) between teachers who teach at elementary levels and those who teach at advanced levels. This is in line with who Pazkhakh (2006) reported that the avoidance strategy is inversely associated with English proficiency level. Since it is assumed that the teachers have a higher proficiency compared to the learners, the propositional-reduction strategy in the teachers' speech is expected to occur less frequently than that of the learners.

Stimulated Recall (SR) protocols, also, offered some insights into how these findings can be interpreted (see Appendix 2 for sample SR protocols). The overall theme of the responses obtained through SR indicates that teachers who taught advanced level learners used more propositional reduction strategies such as topic avoidance 
International Journal of Applied Linguistics \& English Literature

ISSN 2200-3592 (Print), ISSN 2200-3452 (Online)

Vol. 1 No. 7; November 2012 [Special Issue on Applied Linguistics]

and message abandonment than their elementary-level counterparts. This can be attributed to some reasons like language proficiency of teachers, language proficiency of learners. Some advanced teachers introspectively tended to cut the rest of the message because they thought that learners could guess the entire message due to context richness and redundancy in the linguistic content. Some others abandoned the message due to the gap of their knowledge between themselves and the learners. In other instances, the teachers themselves didn't retrieve the correct word. At the elementary level, it is believed the findings can be attributed to the fact that teachers avoid message abandonment since they are not sure of the learners' comprehension. Thus, they convey the whole message to the learners. Altogether the findings of this study are supported by Tarone (1977).

Sometimes, message avoidance occurs as a result of cultural differences. Under such circumstances, the teacher may find the cultural load of the message to be in conflict with the local culture of the EFL classroom context. The number of students might also play a role in teachers' avoidance or abandonment strategy employment. It happens that some students are more active and verbal in the classroom interaction processes, which curtails the interaction between the teacher and one student at the cost of initiating another interaction with a more actively participating student. Age differences between the teachers and the learners, teacher and learner motivation, teacher and learner traits such as introvertedness or extrovertedness of both the teachers and the learners along with many other context-specific factors may also have contributed to the current results.

For teachers, a consciousness of strategies can enrich an awareness of their classroom performance. Syllabus designers can benefit from the findings especially through anticipating teacher-employed strategies in designing various tasks and the role they may play in task implementation. Teacher training programs can more explicitly draw implications from these and other similar findings. It is suggested that future lines of research can shed more light on the different context-specific aspects of strategy employment on both learners' and teachers' part. Awareness of strategies through classroom instruction can, indeed, be a fruitful area of study in SLA, and can accordingly have implications for research, theory and practice in a variety of ways.

\section{References}

Applegate, J. L. (1980). Adaptive communication in educational contexts: A study of teacher's communication strategies. Communication Education, 29,158-170.

Ansarin, A. (2003). Still a new inventory communication strategies? The case of Iranian EFL learners. Tabriz University Faculty of Literature and Human Science Journal, 46, 17-43.

Bialystok, E. (1983). Some factors in the selection and implementation of communication strategies. In C. Faerch and G. Kasper (Eds.), Strategies in interlanguage communication (pp.100-117). London: Longman.

Bialystok, E. (1990). Communication strategies: A psychological analysis of second language use. USA: Blackwell Publishers.

Brown, H. (2000). Principles of language learning and teaching (4th Ed). NY: Longman.

Canale, M. (1983). From communicative competence to communicative language pedagogy. In J. C. Richards and R. W. Schmidt (Eds.). Language and communication (pp. 2-27). Harlow, UK: Longman.

Chen, S. Q. (1990). A study of communication strategies in interlanguage production by Chinese EFL learners.

Language Learning, 40, 155-187.

Cohen, A and Dornyei , Z. (2002). Focus on the Language Learner: Motivation, styles and strategies. In N.

Schmitt (Ed.) An introduction to applied linguistics (pp. 170-190). London: Arnold .

Cook,V.(1993). Linguistic and second language acquisition. London : Macmillan Press.

Dordinezhad, F., Ashori, M. and Hakimi, H. (2011). Communicative curriculum perceived by Iranian language teachers. Procedia Social and Behavioral Sciences, 15, 1761-1765.

Dornyie, Z. and Scott, M. (1997). Communication strategies in second language: Definitions and taxonomies. Language Learning, 47(1), 173-211.

Dornyie, Z. (2007). Research methods in applied linguistics. Oxford: Oxford University Press.

Ellis, R. (1994). The study of second language acquisition. Oxford: Oxford University Press.

Ellis , R. (2004). Task based language learning and teaching. Oxford: Oxford University Press.

Faerch, C., and Kasper, G. (1983a). Strategies in interlanguage communication. Harlow, UK: Longman

Faerch, C., and Kasper, G. (1983b). Plans and strategies in foreign language communication. In C. Færch and G. Kasper. (Eds.), Strategies in interlanguage communication (pp.20-60). London: Longman.

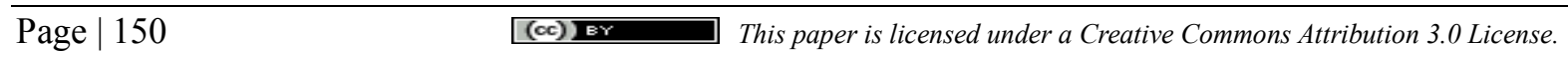


International Journal of Applied Linguistics \& English Literature

ISSN 2200-3592 (Print), ISSN 2200-3452 (Online)

Vol. 1 No. 7; November 2012 [Special Issue on Applied Linguistics]

Gass, S. M., and Selinker, L. (1994). Second language acquisition: An introductory course. Hillsdale, N. J.: Lawrence Erlbaum.

Haastrup, K., and Phillipson, R. (1983). Achievement strategies in learner/native speaker interaction. In C. Færch and G. Kasper (Eds.), Strategies in interlanguage communication (pp. 140-158). Harlow, UK:

Longman.

Halavais ,C. and Petrick, J. (2006). Communication theory. [Online] wikibooks retrieved in 2011, April, from http://upload.wikimedia.org/wikimedia/en-labs/5/51/Communication_Theory.pdf

Jamshidnejad, A. (2011). Developing accuracy by using oral communication strategies in EFL interactions. Journal of Language Teaching and Research, 2(3), 350-536.

Kasper, G. and Kellerman, E. (1997). Communication strategies: Psycholinguistic and sociolinguistic perspectives. Harton, UK: Longman.

Lammers, W. J., and Badia, P. (2005). Fundamentals of behavioral research. California: Thomson and Wadsworth .

Lynch, T. (1996). Communication in the language classroom, Oxford: Oxford University Press.

Mackey, A. and. Gass, S. M. (2005). Second language research: Methodology and design. Mahwah. N.J: Lawerence, Erlbawn.

Mei, A. (2010). Use of communication strategies by Chinese EFL learners. Chinese Journal of Applied Linguistics, 33(3), 1-15.

Nakatani, Y. (2006). Developing an oral communication strategy inventory. The Modern Language Journal, 90(2), 1-15.

Paribakht, T. (1985). Strategic competence and language proficiency. Applied Linguistics, 6, 132-146.

Pazhakh, A. (2006). An Investigation on Iranian EFL Learners' Application of Avoidance

Strategies in Their Writings. Iranian Journal of Language Studies (IJLS), 1(1),1-15

Poulisse, N. (1990). The use of compensatory strategies by Dutch learners of English. Dordrecht: Foris.

Rabab'ah, G. (2003). Communication problems facing Arab learners of English. Journal of Language, Learning, 3(1), 180-19.

Richards, J. C. and Platt, J. (1992). Longman dictionary of language teaching and applied linguistics. Beijing: Foreign Language Teaching and Research Press.

Slezak-Swat, A. (2008).Components of strategic competence in advanced foreign language users. Doctoral dissertation. University of Slesia. [Online] Retrieved on December 17, 2011 from:

http://www.sbc.org.pl/Content/12751/doktorat2945.pdf.

Tarone, E. (1977). Conscious communication strategies in interlanguage: A progress report on TESOL.

Washington, D.C: TESOL.

Tarone, E. (1980). Communication strategies, foreigner talk and repair in interlanguage. Language Learning, 30, 417-431.

Tarone, E. (1981). Some thoughts on the notion of communicative strategy. TESOL Quarterly, 15, 285-95.

Tarone, E., and Yule, G. (1987). Communication strategies in East-West interactions. In L. E. Smith (Ed.), Discourse across cultures: Strategies in world English (pp. 49-65). Hemel Hempstead, UK: Prentice Hall.

Taron, E., and Yule, G. (1989). Focus on language learner. Oxford: Oxford University Press

Van Lier, L. (1988). What's wrong with classroom talk? Prospect, 3, 267-83.

Van den Berg, M. (1988). Long term accommodation of (ethno) linguistic groups toward a societal language norm. Language and Communication, 8, 251-269.

Wood, J. (2011).Communicative language teaching (CLT) and communication strategies (CSs). Theory and practice. 名古屋外国語大学現代国際学部 紀要 第 7,231-243. [Online] Retrieved on December 18, 2011 from: http://library.nakanishi.ac.jp/kiyou/gendaikokusai(7)/08.pdf

Ya-ni, Z. (2007). Communication strategies and foreign language learning. US-China Foreign Language, 5(4), $1-24$

Yarmohammadi, L. and Seif, S.(1992). More on communication strategies: Classification, resources, frequency and underlying processes. IRAL, 30,123-232. 


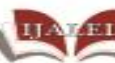

International Journal of Applied Linguistics \& English Literature

ISSN 2200-3592 (Print), ISSN 2200-3452 (Online)

Vol. 1 No. 7; November 2012 [Special Issue on Applied Linguistics]

\section{Appendix 1:}

Integrated model of strategies

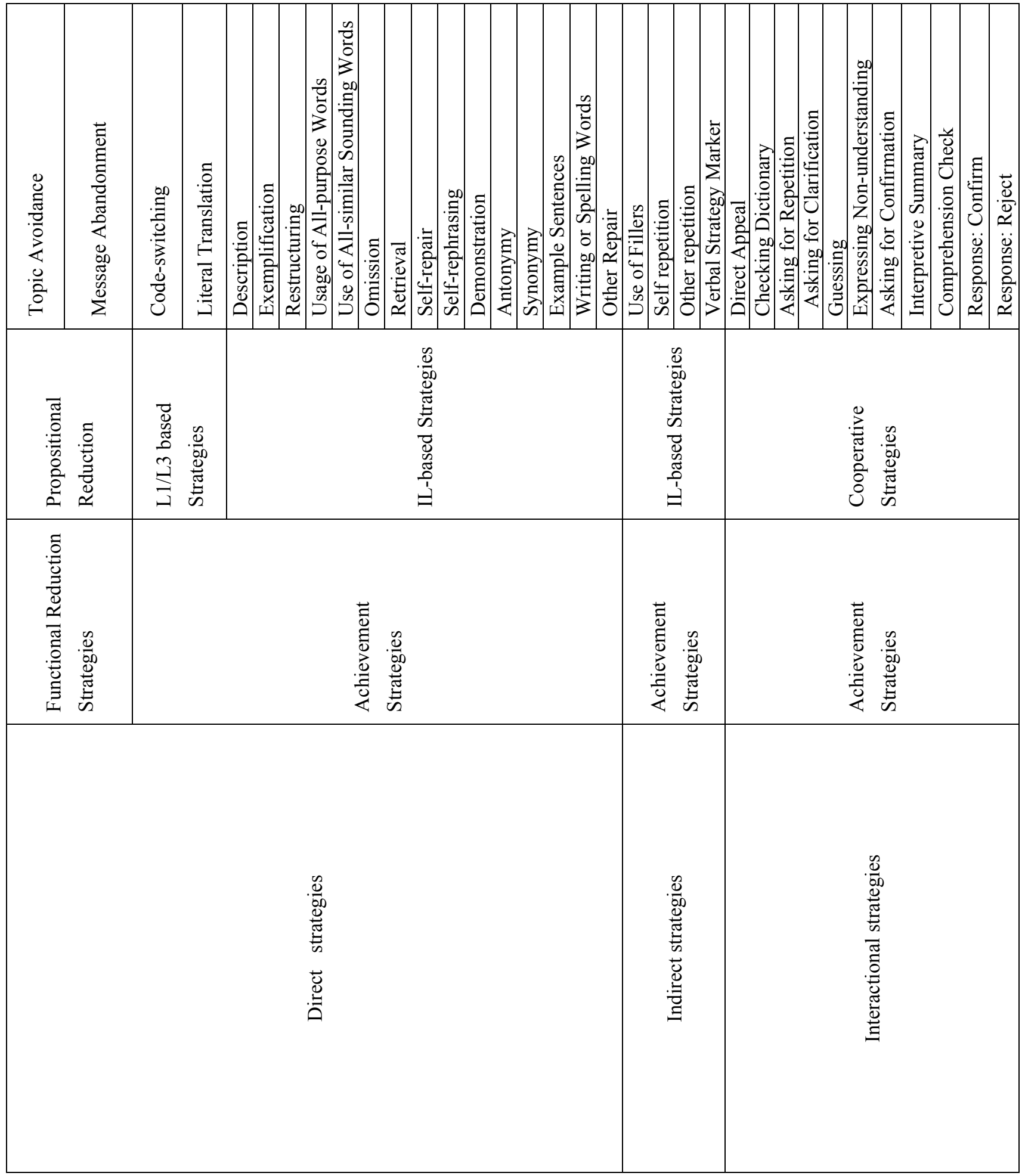


International Journal of Applied Linguistics \& English Literature

ISSN 2200-3592 (Print), ISSN 2200-3452 (Online)

Vol. 1 No. 7; November 2012 [Special Issue on Applied Linguistics]

\section{Appendix 2}

\section{STIMULATED RECALL PROTOCOL SAMPLE 1:}

An advanced-level teacher was asked the following question: (Naj)

Please listen to this track. Why do you use this strategy?

The second author plays the audio recorder (Naj, 2, 22:6)

T: $\quad$ P.C stands for police constant... sorry, police constable.

S: constable?

T: the police in the army with the lowest rank.You know Afsar has the highest rank, he has the lowest rank, it means Paseban

Teacher's response: $\underline{O k}$, in this situation I really didn't know how to translate afsar. So I had to tell it in Persian.

\section{STIMULATED RECALL PROTOCOL SAMPLE 2:}

An elementary-level teacher was asked the following question: (Elem)

Can I ask you why didn't you translate 'kamanche'.

The second author plays the audio recorder (Elem , 1,55:7)

T: what can you play Saeed?

S: violin and kamanche.

T: can you play Kamanche?

S: $\operatorname{yeah}(\ldots)$

Teacher's response : To tell the truth, I didn't know the exact meaning of it . I think there isn't any exact word corresponding to 'kamanche'. The other reason is that if I looked it up the dictionary, the essence of interaction would fade away. The easiest way for me is using 'kamanche' as in Persian. 
International Journal of Applied Linguistics \& English Literature

ISSN 2200-3592 (Print), ISSN 2200-3452 (Online)

Vol. 1 No. 7; November 2012 [Special Issue on Applied Linguistics]

\section{STIMULATED RECALL PROTOCOL SAMPLE 3:}

Another elementary-level teacher was asked the following question (Noro)

Can I ask you why didn't you say the other meanings of the verb "get"

The second author plays the audio recorder (Noro, 1, 40: 90)

T: get means here a little more ... get has some meanings, one of them of them is to catch.

Teacher's response: It is not necessary for them to know all of the meanings of that verb. That's enough for them to know one or two meaning of it. If I said all of the meanings they would be baffled.

STIMULATED RECALL PROTOCOL SAMPLE 4:

Another teacher teaching advanced level learners was asked the following (MAH1)

Why didn't you translate sabegheye kar?

The second author plays the audio recorder (MAH1,1,40:00)

T: We decided to go to ANTALIA

S: maybe we go after 6 years

T: where?

S:after my father retired [...] become retired

T: after 8 years or after your father become retired?

S:my father teaches in Sepah, Dabirestan and he has Sabegheye kar in that Dabirestan .

T:ahan(... yes (... So after five years of retirement he can go.

S: No, no, not five years. It is a special place in army that travel for five year, not for my father

Teacher's response: I wanted to continue the conversation and the word was rather difficult. However I should have said that word but when I saw that student speaks after awhile, I didn't want to interrupt his speech. 